\title{
REVIEW
}

\section{Pros and cons of using seabirds as ecological indicators}

\author{
J. M. Durant ${ }^{1, *}$, D. Ø. Hjermann ${ }^{1}$, M. Frederiksen ${ }^{2}$, J. B. Charrassin ${ }^{3}$, Y. Le Maho ${ }^{4}$, \\ P. S. Sabarros ${ }^{1}$, R. J. M. Crawford ${ }^{5,6}$, N. Chr. Stenseth ${ }^{1,7}$ \\ ${ }^{1}$ Centre for Ecological and Evolutionary Synthesis (CEES), Department of Biology, University of Oslo, PO Box 1066 Blindern, \\ 0316 Oslo, Norway \\ ${ }^{2}$ National Environmental Research Institute, Department of Arctic Environment, Aarhus University, Frederiksborgvej 399, \\ 4000 Roskilde, Denmark \\ ${ }^{3}$ Laboratoire d'Océanographie et du Climat: Expérimentation et Approches Numériques, Département Milieux et \\ Peuplements Aquatiques, Muséum National d'Histoire Naturelle, 43 rue Cuvier, 75231 Paris Cedex 05, France \\ ${ }^{4}$ Institut Pluridisciplinaire Hubert Curien, Département Ecologie, Physiologie et Ethologie, UMR 7178 CNRS-ULP, \\ 23 rue Becquerel, 67087 Strasbourg Cedex 2, France \\ ${ }^{5}$ Marine and Coastal Management, Department of Environmental Affairs and Tourism, Private Bag X2, Rogge Bay 8012, \\ South Africa \\ ${ }^{6}$ Animal Demography Unit, Department of Zoology, University of Cape Town, Rondebosch 7701, South Africa \\ ${ }^{7}$ Institute of Marine Research, Flødevigen Marine Research Station, 4817 His, Norway
}

\begin{abstract}
Climate change and overfishing are increasingly causing unanticipated changes in marine ecosystems (e.g. shifts in species dominance). In order to understand and anticipate these changes, there is a crucial need for indicators that summarise large quantities of information into a few relevant and accessible signals. Seabirds have been suggested as good candidates for ecological indicators of the marine environment; however, few studies have critically evaluated their value as such. We review the role of seabirds as ecological indicators, and discuss their limitations and drawbacks, as compared to other types of indicators. In addition, we highlight the statistical consequences of inverse inference when using seabird data as indicators. We discuss the use of integrated indices and the use of seabirds as autonomous samplers of the marine environment. Finally, we highlight the necessary steps preceding the use of seabirds as indicators. We conclude that, in order to use seabird time series properly, the use of recent advances both in statistics and in remote sensing is a way to move forward. This, along with the assessment of their usefulness, should enable us to use seabird indicators appropriately for managing urgent conservation problems.
\end{abstract}

KEY WORDS: Food chain · Oceanography · Statistics · Conservation · Ecosystem-based management • Telemetry

Resale or republication not permitted without written consent of the publisher

\section{INTRODUCTION}

Seabirds, and marine top predators in general, are conspicuous and high-profile components of marine ecosystems, feeding at a wide range of trophic levels and in a broad spectrum of marine habitats - from the littoral to the open ocean — throughout the world's marine envi- ronments. Their position at or near the apex of most marine food chains makes many seabirds ideal sentinel organisms for monitoring changes within marine ecosystems. At least, this is the common view. Numerous studies have concluded that seabirds are good indicators of whichever environmental variable is tested (see electronic supplement Table S1, available as supplementary 
material at www.int-res.com/articles/suppl/c039p115_ app.pdf). Several books have been written on the subject (e.g. Furness \& Greenwood 1993, Boyd et al. 2006), as well as reviews (e.g. Bost \& Le Maho 1993) and special issues in journals (ICES 2003, Piatt et al. 2007a). Seabirds and marine mammals have also been used to investigate the presence and concentration of pollutants in areas utilised by these animals (e.g. Furness \& Camphuysen 1997, Mössner \& Ballschmiter 1997, Beckmen et al. 1999). More recently, it has been suggested that top predators such as seabirds provide an integrative view of the consequences of environmental variability on ecosystems (see Jenouvrier et al. 2003). In the present paper, we critically review the proposed use of seabirds as indicators of ecosystem change and ecosystem health. We focus on the use of behavioural and demographic measurements from seabird populations as ecological indicators. However, we do not consider in this paper the use of seabirds as indicators of ecosystem pollution through the measurement of tissue contamination.

Before focusing on seabirds, we must define what an indicator is, and also define its corollary-what a good indicator is. Several papers have suggested criteria for selecting indicator taxa (reviewed by Bibby 1999, Hilty \& Merenlender 2000, Gregory et al. 2003). We summarise the most important criteria as follows:

(1) The candidate indicator should provide a representative picture of what it is supposed to indicate (e.g. 'ecosystem changes due to climate change' or 'ecosystem health').

(2) The indicator should be simple and respond rapidly. It needs to capture the complexities of the ecosystem yet remain simple enough to be easily and routinely monitored. Some common problems are that the response of the indicator can be confounded with other variables, that indicator response could vary with location, or that indicator response could be lagged in time relative to the changes in the ecosystem.

(3) The indicator should indicate the conditions on a relatively large spatial scale. In other words, the response of the indicators in one or a few locations should indicate the state of the ecosystem in a larger area (such as an ocean).

(4) It can be an advantage if the indicator has a reference value against which comparisons can be made so that users are able to assess the significance of the values associated with it. Climate change has led to shifts in phenology in many species in a wide range of taxa (Crick et al. 1997, Forchhammer et al. 1998, Walther et al. 2002, Jonzen et al. 2006, 2007), the most visible to the public being birds and mammals (flagship indicators) (Caro \& O'Doherty 1999). However, it is unclear how we should interpret these shifts without some sort of a measure, a yardstick, that reflects how much a species phenology should theoretically change to match a given environmental change (Visser \& Both 2005). Without such a yardstick, it is not possible to use the observed change in, for instance, phenology, as an indicator of environmental change (Visser \& Both 2005).

It is thus a challenge to produce an indicator, particularly a good one. Accordingly, we may question whether seabirds can serve as useful indicators of ecosystem health at all, as so often advocated in ornithology papers (Furness \& Camphuysen 1997, Harding et al. 2005, Piatt et al. 2007a). In this review, we focus in particular on the following:

(1) What do we need ecological indicators for and how should they be used?

(2) Why should we consider seabirds as indicators?

(3) Problems of using seabirds as indicators

(4) How can these problems be overcome?

We also present results from a literature survey on the use of birds as bioindicators.

\section{USE OF ECOLOGICAL INDICATORS}

Indicators are used to enhance communication between partners, as well as transparency, effectiveness and accountability of management of a complex system. They should provide a readily understood tool for describing the state of the system and for assessing trends regarding sustainable development objectives. In other words, indicators summarise large quantities of information into a few relevant signals for the user (e.g. decision-makers).

Among indicators, bioindicators, or more particularly ecological indicators, are usually used to communicate information about the health of ecosystems. These indicators can be used to assess the condition of the environment, to provide an early warning signal of changes in the environment, or to diagnose the cause of an environmental problem. Because ecosystems are often complex (e.g. Ciannelli et al. 2005) and hence difficult to encompass in their totality, such indicators are very useful for decision-makers. For example, bioindicators are currently used for conservation programs (e.g. seabirds, CCAMLR 2008). There is a need for such 'health of the ecosystem' information as biodiversity and its conservation are becoming the preeminent factors in management considerations of decision-makers (Heslenfeld \& Enserink 2008), and society is increasingly confronted with fundamental global environmental changes often caused by human activities.

When considering marine animals as autonomous samplers of the marine environment (Box 1), ecological indicators will not do better than satellites and other automated devices, such as moored buoys, to indicate 
Box 1. Seabirds as oceanographic autonomous samplers (see Appendix 1)

- A valuable input from electronically tagged seabirds is their ability to indicate and sample places of enhanced biological activity.

- Their 2D (at the sea surface) or 3D (at depth) movements include, by definition, information on prey location.

- Information on feeding behaviour combined with feeding location provides data on prey distribution and relative prey abundance. The relevance of this concept depends on:

(1) the validity of proxies used to infer feeding behaviour and prey distribution from seabird movements (2) the scale at which the relationships between the seabird and the prey field is examined.

- Track-based data can provide mesoscale to large scale information on the presence of prey and may be more efficient with long-ranging seabirds.

- At smaller scales, direct feeding measurements (or validated proxies) may be required in addition to high resolution data on bird position at the sea surface and at depth.

- Future challenges include:

(1) increasing the sample size and developing adequate methods to analyse the many data acquired

(2) validating with concurrent vessel-based campaigns the behavioural and feeding proxies of prey distribution and relative abundance.

- Given the steady technological progress and decreasing costs, the concept of using electronically tagged seabirds as bioindicators has a promising future.

changes in the atmosphere or in the surface water (e.g. surface chlorophyll or temperature). However, while non-ecological indicators (e.g. physical parameters) affect all elements of the ecosystem, they cannot tell us how changes in the physical environment (e.g. climate change) affect the ecosystem. While physical coverage of the ocean by conventional means is constantly improving with the development of new technologies (e.g. deployment of 3000 Argo autonomous profilers in oceans worldwide; Roemmich \& Owens 2000), high latitude oceans remain poorly sampled, with data generally showing low spatial and temporal resolution. By deploying miniaturized sensors on diving seabirds (and marine mammals), and using new techniques of telemetry, it is possible to acquire 3-dimensional (3D) hydrographic physical data (e.g. temperature and salinity) at high resolution in predators' foraging areas. Such data constitute a cost-efficient and valuable complement to conventional data, which, beyond their utility to describe the predators' habitat, can be used to address oceanographic questions (in terms of horizontal and vertical, as well as temporal scales) through large periods of the year (e.g. Charrassin et al. 2004, Sokolov et al. 2006).

Quantifying the abundance of widespread fishery resources (i.e. prey populations for the seabirds), knowing that this assessment depends on their availability and their accessibility, is challenging in all habitats (Johnson 1980), and even more so in habitats where seabirds habitually forage. Survey-based data of marine invertebrates and fish are (if any exist) typically scarce, except for data for commercially exploited species, and tend to be low resolution both temporally and spatially. Moreover pelagic fishes can exhibit ship avoidance (Hunt et al. 1990), adding to the difficulty of making a good estimate of their abundance. The high mobility and large foraging range of seabirds is thus of particular interest: (1) since their prey, often pelagic fishes, usually concentrate in shoals which are mobile in 3 dimensions and not uniformly distributed, (2) since conventional fish stock assessment will become increasingly expensive with steadily increasing fuel costs for ships (even before oil prices started rising, many coastal states were unable to afford ship-based surveys of their marine waters). Furthermore, assessment from ships is time consuming and can be severely restricted by sea conditions or sea ice at high latitudes (Bost \& Le Maho 1993). Thus, there are several reasons why the use of predator data to assess abundance of e.g. pelagic fishes has been receiving considerable attention. Monitoring biological changes by monitoring the catch of predators is effective and can be a valuable addition to survey-based data. For example, seabird feeding habits, growth rates and survival have been related to local prey abundance in several studies (Cairns 1987, Monaghan 1996, Montevecchi \& Myers 1996). Through our literature survey, we found that it is this tight trophic interaction between consumer and resource that provides the best opportunities for using seabirds as indicators (Table S1).

The main challenge of using ecological indicators is to use them for the purpose for which they are best suited. To be an indicator of change, an organism must show a response to this change. For instance, plasticity and adaptability may hide responses and thus make organisms difficult to use as indicators-e.g. animals can compensate for environmental constraints by increasing their energy expenditure. Nevertheless, such an increase cannot exceed a certain level, as excessive use of resources will impair body condition and reduce fitness. Also seabirds have reserves in their timeenergy budgets that allow them to increase effort at times when foraging or flying may be more difficult; thus they can compensate for low food availability (Cairns 1987). In other words, behavioural parameters (e.g. increase in effort) are more sensitive to change than demographic ones (e.g. breeding success) and should be preferred as indicators.

Climate variability affects animals directly through its effect on their physiology (including moult, metabolic and reproductive processes), as well as indirectly 
through its effects on their biological (e.g. predator, prey, within-population interactions, disease) and physical (e.g. breeding habitat, ambient temperature) environments. For instance, the physical environment affects feeding rates and competition through conditions that favour one species over another. Since prey populations fluctuate in response to climatic changes, the main indirect influence of climate on marine predators is through the regulation of food availability, suggesting that marine predators can be good indicators of the effects of climate variability on the ecosystem. However, the physiological response to change is rarely linear. This was advocated by Cairns (1987), who predicted that parameters of seabird biology and behaviour would vary in a curvilinear fashion with changes in food supply. This also applies to other organisms used as ecological indicators, such as marine mammals. Consequently, depending on which part of the curvilinear relationship is relevant, these animals are in most circumstances unlikely to reflect subtle or continuous changes and therefore should not be used as indicators of such changes. However, they may perform well as binary or threshold indicators (Crawford et al. 2006a, Montevecchi 2007, Piatt et al. 2007b) that signal changes from 'good' to 'bad', and vice versa. By pointing out the threshold value of environmental change affecting an ecosystem, ecological indicators are thus a sensitive and powerful tool for providing information about the health of ecosystems.

\section{NEED FOR SEABIRDS AS INDICATORS}

The use of seabirds as indicators of marine resources is a traditional practice among fishers. In Norway, fishers use the fishing pattern of gulls (e.g. herring gull Larus fuscus) to locate mackerel Scomber scombrus and herring Clupea harengus schools (D. Ø. Hjermann pers. comm.). This is made possible by the link between feeding habits of seabirds and local prey abundance (Table S1; Cairns 1987, Monaghan 1996, Montevecchi \& Myers 1996).

Seabirds are usually at or near the top of pelagic or benthic trophic chains. There is evidence that seabird populations and reproductive performance are regulated by prey abundance (Birkhead \& Furness 1985, Hunt et al. 1986, 1990) and thus this may reflect environmentally induced fluctuations in prey availability. Some seabirds can be considered as specialist feeders that rely on one or a group of prey species such as small shoaling fishes, squid or planktonic crustaceans (Brown 1980, Croxall 1984, 1987, Cairns 1987, Ricklefs 1990). In cold-water marine ecosystems, a few species of small pelagic fishes are key species of the ecosystem (i.e. they have a major effect on the ecosystem as a whole). By channelling energy and nutrients from planktonic primary and secondary producers to top predators, these key species exert a major control on the energy flows of the ecosystem (Cury et al. 2000). Seabirds foraging mainly on these key species may consequently be good indicators of the state of the ecosystem. A generalist predator can switch its food regime to match the relative abundance of marine resources, whereas a specialist predator will be rapidly affected by any climate-induced change on its main prey. The effects of changes in prey resources on seabirds (climate or fishery induced) are usually very rapid, due to short trophic chains, particularly in northern and southern seas (but see Section 4.3. describing lagged effects). Trophic chains can be more complex at lower latitudes than at higher ones (Ciannelli et al. 2005), raising some doubts about using seabirds as indicators, for instance in the tropics.

In several systems, seabirds feed on abundant forage fishes that are also intensively exploited by fisheries (e.g. Crawford et al. 2006b). Although seabird parameters may be strongly correlated with measures of fish abundance (e.g. Crawford et al. 2006a, Crawford 2007), and hence be indicators of fish abundance, it is not always clear which factor is driving the changes in the forage fish populations, whether it is fishing or the climate. In such instances, examination of the responses of a suite of predators (and other organisms) may provide greater insight into the controlling factors than consideration of a single predator. For example, off South Africa a recent eastward displacement of breeding sites of several seabirds that compete with fisheries for food conformed not only to an eastward displacement of their main prey species, but also to eastward expansions in the distributions of other seabird species that do not subsist on commerciallyexploited prey (Crawford et al. 2008b). This suggests some influence of climate.

Seabirds are generally wide-ranging and highly mobile predators (Bost \& Le Maho 1993). Because marine resources are often unpredictable, patchy and scattered over large areas, it is generally assumed that seabirds have difficulty finding food (Weimerskirch 2002). However, patchiness and predictability of marine resources are complex factors when considering the foraging patterns of seabirds; predictability in oceanic waters is generally low (Weimerskirch 2007) but seabirds tend to return consistently to generally the same area on the continental shelf edge. Indeed, seabirds often rely on quite predictable mesoscale structures for foraging, such as eddies, fronts, zones of upwelling, river plumes, or strong flows at the interface between 2 water masses where prey biomass is likely to be elevated (Strass et al. 2002, Weimerskirch et al. 2007). This is important in the context of using 
seabirds as indicators, since the mesoscale is the spatial scale at which important processes of fish population dynamics, such as recruitment (stock replenishment), is expected to be linked to ocean productivity (Cury et al. 2008). In recent years seabirds are increasingly being used to sample the physical and biological properties of the marine environment in real time (Wilson et al. 2002a). For example, the movements and diving activity of individual animals have been used to infer large- to mesoscale prey resource distributions and to ground-truth oceanographic conditions over time periods (e.g. winter season) and in locations (e.g. Southern Ocean) that are otherwise difficult to sample synoptically by more conventional means (Ancel et al. 1992, Weimerskirch et al. 1995). Current telemetry techniques deployed on foraging seabirds can provide information on prey distribution; e.g. in determining location and depth of a prey patch (Charrassin \& Bost 2001, Wilson et al. 2002a), and animal-borne instruments can be used to explore inaccessible faunas, e.g. using seal-mounted cameras to explore fauna beneath $100 \mathrm{~m}$ thick ice shelves (Watanabe et al. 2006).

These factors explain how the demographic parameters of seabirds have been correlated with ENSO effects (Boersma 1978, Schreiber \& Schreiber 1984, Hunt et al. 1990), with aspects of the physical environment (Croxall et al. 1988, Aebischer et al. 1990, Jouventin \& Weimerskirch 1991, Smithers et al. 2003, Crawford et al. 2006a, Crawford 2007, Frederiksen et al. 2007, Le Bohec et al. 2008) and with prey availability (Anderson et al. 1980, Monaghan et al. 1989, Ainley \& Boekelheide 1990, Gaston et al. 2005) in the North Sea, Southern Atlantic, Southern Ocean and Farallon Current (see also Table S1). Accordingly several demographic parameters or life history traits - such as population size, duration of foraging trips, changes in body mass and offspring growth rate-have been suggested as suitable environmental monitors by the Convention of Antarctic Marine Living Resources (CCAMLR 2008).

\section{PROBLEMS WITH SEABIRDS AS INDICATORS}

Many studies have concluded that seabirds are useful bioindicators. Most of these conclusions have resulted from correlation studies relating prey (usually number of prey) to various biological variables (e.g. breeding success) measured in seabird colonies (Table S1). However, few studies formally test the feasibility and/or usefulness of seabirds as bioindicators (but see Parsons et al. 2008), but simply conclude, on finding a significant statistical correlation, that the population studied can be used as a bioindicator. The basic requirements for developing an indicator (Bibby
1999, Hilty \& Merenlender 2000, Parsons et al. 2008) are also seldom taken into account, and there are significant limitations in the use of seabirds as indicators in data collection procedures, and as a result of the biology of birds. These limitations are described in the following sections.

\subsection{Inverse inference}

The major drawback of correlation analyses is that a statistical correlation between 2 variables does not necessarily imply a cause-effect relationship (Votier et al. 2008). Leaving this problem aside, in most studies advocating the use of seabirds as indicators there is a lack of consideration of the difficulties of 'inverse inference' (Box 2), i.e. using the dependent variable to estimate the explanatory variable. In other words, while prey abundance explains well the breeding success of a seabird, the reverse is not necessarily true. As shown in Box 2 (and developed in Appendix 2), if the relationship between seabirds and prey has been estimated using ordinary regression, using seabirds as indicators for prey abundance has a tendency to exaggerate changes in prey abundance (overestimate prey abundance when breeding success is high and underestimate it when breeding success is low). Furthermore, while bird populations may be strongly affected by environmental factors such as changes in climate, they are at the same time affected by other factors, such as anthropogenic threats (e.g. pollution; Schreiber \& Burger 2002). Hence the observation of change in a bird population does not necessarily indicate climatic

Box 2. Statistical considerations: inverse inference (see Appendix 2)

\footnotetext{
- Inverse inference-predicting prey abundance from predator performance based on a relationship established in other areas/years - is associated with particular difficulties:

(1) the parameter uncertainty in the functional response

(2) the functional response typically has a sigmoid shape, increasing the uncertainty of prey density

(3) there may be uncertainty about the abundance of alternative prey.

Statistically, Points $1 \& 2$ can be corrected.

- In addition, when ordinary regression is used to relate predator performance to prey abundance, inverse inference will lead to a bias: prey abundance will tend to be overestimated when the latter is above the mean, and underestimated when it is below the mean.

- By using an alternative to ordinary linear regression (standardized major axis regression), i.e. 'Type II' regression, this bias is removed.

- This method does not distinguish between 'dependent' and 'independent' variables and allows for error in both variables.
} 
or environmental change, but may reflect changes in several variables. For instance, variation in breeding performance can be influenced by factors other than oceanographic changes, such as extreme weather, predation and parasites (Cairns 1987).

\subsection{Ecosystem control and seabirds' role}

Aquatic food webs have been studied intensively with respect to the effects of trophic interactions between consumer and resource on species composition and abundance; different types of control mechanisms have been suggested. The first control type is when the regulation of food web components is caused by the environment, e.g. by primary producers (bottom-up control). The second control type is an opposite mechanism, when the regulation of lower food web components is caused by one or several upper-level predators (top-down control). Finally, in many marine ecosystems, the mid-trophic (zooplankton-feeding) level tends to be occupied by a few abundant species, usually pelagic schooling fish. These species often fluctuate greatly in abundance, leading to a waspwaist control of the ecosystem (i.e. controlling both primary and secondary producers as well as predators). Recent studies reveal that control in marine food webs is dynamic and can alternate between bottom-up and top-down, or be a combination of both (Hunt et al. 2002, Litzow \& Ciannelli 2007, Cury et al. 2008). This suggests that there is an oscillating control mechanism (Hunt et al. 2002) where top-down and bottom-up forcing governs marine food webs alternately depending on the climate phase (e.g. in the southeastern Bering Sea, which is characterized by a top-down control during warm regimes - early ice retreat and warm water during the spring bloom-and a bottom-up control during cold regimes). In addition, in a normal bottomup controlled system, anthropogenic pollution and overexploitation of the food resource will add topdown pressures on the system.

Depending on the mode of ecosystem control, seabirds may be more or less suitable as indicators of their food supplies. For instance, the top-down model postulates that predation controls community organization. In other words, any change in predator numbers (e.g. seabird populations) will be propagated to the lower trophic levels. In this case, the seabirds are not indicators, as the changes in the trophic chain result from the seabirds themselves, or from the action of other top predators (mammals) or fisheries. On the other hand, when bottom-up control is dominant, top predator populations are unlikely to be regulated through densitydependent prey depletion (Birt et al. 1987), because prey abundance will be controlled by production at lower trophic levels. Instead, seabird foraging success, breeding productivity and ultimately population size are likely to track spatial and temporal variation in prey abundance. If, for instance, the breeding success of several species at the same location is highly correlated over time, the system is likely to be bottom-up controlled. However, while reflecting a change in the food conditions, any change in seabird numbers in this situation usually responds with a lag of several months or even years (Thompson \& Ollason 2001, Thompson \& Grosbois 2002).

\subsection{Time lags}

Temporal lags in the response of populations to broad-scale climate indices, such as the North Atlantic Oscillation Index (Hurrell 1995), are widespread in both terrestrial and marine environments (Forchhammer et al. 2001, Ottersen et al. 2001, Stenseth et al. 2002). In marine systems, lagged responses span many trophic levels and have been observed for seabirds (Durant et al. 2004b). Life history traits (e.g. timing of reproduction, number of chicks produced) show sensitivity to climate indices (Durant et al. 2004b), and may influence population dynamics years later when the offspring produced are starting to reproduce for the first time. Life history-induced time lags can be dramatic in long-lived species with delayed reproductive maturity (such as most seabirds). In other words, the effect of climate on seabird populations may or may not take many years to become apparent (Thompson \& Ollason 2001). Its effect is complex and involves a large number of physical and biological processes. This may be a severe drawback to the use of seabird population size as an indicator.

\subsection{Individual plasticity}

A population consists of individuals, each of which may respond to its environment in its own particular way. As a consequence, the impact of environmental change on animal populations is strongly influenced by the plasticity of individuals to adjust key life-history traits (phenotypic plasticity). For instance, individual organisms can alter the expression of a labile trait (e.g. reproductive traits such as timing of reproduction or number of offspring produced) in response to environmental conditions (Both et al. 2004). However, most ecological studies examine environment-dependent trait expression by correlating annual mean values of a labile trait with an environmental variable (e.g. sea surface temperature, North Atlantic Oscillation). Thereby, these studies implicitly overlook the possibil- 
ity of ecological or evolutionary forces affecting individual plasticity within the population (Nussey et al. 2007). Individual response to environment is implicitly assumed to remain constant as climate conditions change; however, this is not always what is expressed at the population level. For instance, the influence of the North Atlantic Oscillation on the timing of hatching of Atlantic puffins Fratercula arctica breeding on the Norwegian coast is not constant (Durant et al. 2004a). In this study, an otherwise negative relationship disappeared completely for $8 \mathrm{yr}$ in middle of the 2 decades studied (Durant et al. 2004a). This regime shift was thought to be linked to a change in age structure of the breeding population, due to previous years with poor reproduction.

The inconstancy of individual response to environment and its effect at the population level can be problematic in the use of seabirds as indicators. One solution could be to use seabirds with low phenotypic plasticity (Reed et al. 2006). However, in the case of an ecological change this may lead to the reduction or even disappearance of the relationship, an event which is informative in itself, but hard to interpret. Likewise, the relationship between environment and biological variables is not necessarily linear. For instance, the breeding success of the puffin population discussed earlier is non-linearly and positively related to the abundance of herring Clupea harengus near the Norwegian coast (Durant et al. 2005), with a plateau effect over a certain threshold in herring abundance. In some extreme cases the relationship can even be binary (Montevecchi 2007). In such cases it is possible to identify threshold values that may be used advantageously as indicators for conservation action.

\subsection{Handling effect}

In addition to surveys at the population level, many studies undertaken on the use of seabirds as indicators have employed the monitoring of individual birds to determine population parameters and life history traits. The consequences of catching birds to identify them, to weigh them (to assess their body condition), or to equip them with instruments for recording behaviour and life history traits, are still poorly understood. However, the potential impact may be constant over time, hence not precluding use of these techniques as monitoring tools. Likewise, seabirds are generally large, comparative to ring or instrument size, seldom handled (very often only once in their lifetime for ringing), and locomotive organs (i.e. wings) are not equipped.

Due to their large size, penguins were the first diving seabirds equipped with data loggers. In the past they have been extensively tagged with flipper bands (in contrast to leg rings for volant seabirds), resulting in a considerable amount of data. They are consequently one of the main species used as indicators of the Southern Ocean. However there has been increasing evidence that flipper bands reduce both breeding success and survival of penguins (Froget et al. 1998, Jackson \& Wilson 2002, Gauthier-Clerc et al. 2004, Dugger et al. 2006). At lower latitudes, this may, however, not be the case (Barham et al. 2008).

This drawback described for penguins is to some extent common for any use of animals as indicators. Indeed, a difficulty is to make sure that the observed effects are actually due to changes in the environmental factors we are interested in (e.g. climate-induced changes in resources), and not to other factors. Similarly, seabirds can only be used as indicators of local to basin-wide physical changes under certain conditions: the life history of the species and the specific local population must be well documented (Parrish \& Zador 2003).

\section{PRODUCING BETTER INDICATORS}

Many time series on seabirds are doubtless of high quality and of immense value towards understanding and preserving marine ecosystems, and ornithologists certainly have a lot to contribute towards strategies in biodiversity conservation. However, there is a need to think about how to use these data more effectively.

\subsection{Statistical correction and proper use of time series}

Some solutions exist to bypass the problem of inverse inference, as described in Section 4.1, such as standardized major axis regression (see Box 2), but are rarely used, even though this is a known problem in biology. Researchers working on allometry and other biometric studies (e.g. Green 2001) have been particularly aware of this issue. To use body mass as an indicator of body condition (e.g. amount of body reserves), a common approach has been to control for body length by performing an ordinary least squares regression between body mass and body length and using the residual (mass controlling for length) as an indicator of body condition. Green (2001) criticized this approach because of the 2 assumptions of ordinary least square regression, ( $\mathrm{Y}$ is affected by $\mathrm{X}$ while $\mathrm{X}$ is strictly independent of $\mathrm{Y}$, absence of measurement error [Box 2]) as well as other issues. As biometric measurements of birds may be used in bioindicator studies, a double statistical problem may arise: (1) body mass may be improperly used as an indicator of body condition; (2) body condition may be improperly used as an indicator of prey abundance. 


\subsection{Alternative use of time series}

Usually indicators consist of single variables measured at one site. Such indicators are often easy to measure and interpret, but at the same time their sensitivity to stress and their integrative power are unknown. This is the case in the majority of the studies of seabirds as indicators (Table S1). However, data collection on seabirds for monitoring purposes is widely performed, and it is possible to combine several data sets on the same species in different locations, or several species at one location, in the same time frame (Box 3). By doing so, it becomes possible to develop integrative indicators showing predictable responses to stressors (see Box 3). Another advantage of this approach is that because field methods usually differ among species or locations, measurement error should be uncorrelated among time series, and application of e.g. principal component analysis (PCA) filters out measurement error in principle. However, while the use of the first principal component from a PCA as a compound ecological indicator is an attractive choice (Box 3), it is linked to some constraints inherent in the linear statistical technique used. For instance, PCA assumes that all the time series used are homogeneous and highly correlated, since variables which are not highly correlated with the others will not be represented in the first principal component. In other words it assumes that the relative contribution of each time series is constant in time, and that no transitory phenomena disturb the series. For example, an extraordinary phenomenon such as an oil accident changing the population parameters of one colony or species in a given year will show up in the time series and can result in a higher (or lower) representation of this variable relative to the others used in the PCA, with no real biological/ecological reason for this.

Box 3. Univariate or multivariate indicators (see Appendix 3)

- Time series of individual aspects of seabird ecology may be unsuitable as indicators of a specific driver such as climate, because they are affected by multiple environmental drivers and/or contain substantial noise (measurement error).

- By combining several correlated variables through e.g. principal component analysis, a compound indicator can be constructed that is unaffected by these idiosyncrasies and draws out the strongest possible common signal.

- This signal should ideally be more strongly related to generic environmental drivers (e.g. climate) than any of the constituent time series.

- The main drawback of such a multivariate indicator is that it is less readily interpretable, and thus may have less appeal to managers, policy makers and the general public.

\subsection{Collation of new types of data}

Remote sensing has been developed over the last 3 decades following the need to better understand the ecology of seabirds and marine mammals (when at sea), and the steady advance in technology (miniaturization of the electronic devices, number and quality of the data measured, memory capacity, etc.). Equipping marine animals with miniaturized electronic devices has transformed them into autonomous samplers of the marine environment (Box 1). This method of determining behaviour allows individuals to be tracked at both their breeding sites on land and their feeding sites at sea (Burger \& Shaffer 2008). Given the importance of obtaining information on prey distribution in order to improve understanding of marine ecosystems, tracking seabirds in their foraging zones is probably a major input to integrated marine studies. Behavioural data are collected by a wide range of telemetric miniaturized devices that can provide information on animal position and movements at sea, diving behaviour, and feeding behaviour (taken here as prey ingestion), although only few studies have reported on the 3 parameters simultaneously. When using predators as bio-indicators, knowledge of foraging movements and diving behaviour provides information on the 2- or 3-dimensional distribution of prey. The latter is inferred from various behavioural proxies for which accuracy of matching with actual prey distribution is scale dependent (Bost et al. 2009). Additional to this feature and of paramount importance in relating climate and seabirds, is the possibility to link at-sea behaviour (and thus indirect prey information) to biotic or abiotic variables, obtained through either remote sensing and historical observations (Nel et al. 2001), or directly via miniaturized oceanographic sensors carried by the birds (Weimerskirch et al. 1995, Charrassin \& Bost 2001). Remote sensing of seabirds is thus a powerful tool, complementary to visual seabird surveys at sea, because it allows key individual parameters to be determined (such as birds' origin, sex, age). In contrast, vessel-based surveys enable acquisition of information on many more individuals than with remote sensing, yet the individual status of each bird remains unknown. Using this tracking approach, it becomes possible to assess atsea distribution according to the marine environment, while accounting for the predators' life-history traits. However, data loggers can have an adverse effect on foraging bird performance, especially in penguins (Ropert-Coudert et al. 2007). This effect depends on the device size and shape, and care must be taken to minimize the size and to streamline the data logger to reduce that impact. Continuing development in the miniaturisation of data loggers is reducing such dele- 
terious effects (Bost et al. 2009). There remain, however, some caveats when using these techniques. Apart from potential inverse inference problems, sample size is still almost inevitably low, due to timeconsuming and thus costly data processing. However, continuing advances in technology are reducing data processing time and costs.

In climate studies, the maintenance of annual timeseries of seabird tracking is to be encouraged, as this will bring new insights into the impact of ecological and environmental changes on prey distribution and abundance, a road already taken in marine mammal studies (e.g. Weise et al. 2006). Such work on seabird tracking will be complementary to land-based demographic studies of the same species. Indeed, it will help to understand changes in the marine ecosystems by establishing relationships between climate-induced physical changes in the ocean, shift in prey distribution, and predator dynamics.

\section{CONCLUSIONS}

Ecological indicators are essential for both science and society in our time of jeopardised biodiversity. Therefore, understanding what differentiates a good indicator from a bad one is crucial. In this review we have illustrated some of the advantages and limitations in the use of seabirds as ecological indicators. We think that using advances in both statistics and remote sensing is the way to go forward. Many studies on seabirds have highlighted their potential usefulness as bioindicators, however most of the time these were a posteriori conclusions, since the studies were not designed for this purpose. While we agree that current monitoring programmes on seabirds should be used for this purpose-indeed many of the ongoing programs are good and should definitely be continued-we advise that the following points are met before starting new monitoring programmes:

(1) Define the objectives clearly by listing goals.

(2) Choose the species according to the objectives. There should always be a sound justification for linking a particular seabird species or group of seabirds with particular pressures.

(3) Conduct a pilot study to test the usefulness of the indicator selected.

(4) Optimally, have a good understanding of the ecosystem functioning (e.g. trophic interactions) and be aware of the sensitivity of the system to exceptional events.

This should enable us to choose seabird indicators with greater clarity and to employ them in a more useful way for solving urgent conservation problems.
Acknowledgements. Funding was provided by the Norwegian Research Council (J.M.D. and D.Ø.H. thank the 'Fribio' programme for supporting the Mico project), Marie Curie actions under FP6 of European Commission (MEST-CT-2005-020932) support for P.S.S. through the CEES-MCO training site. We thank C. Le Bohec and G. Ottersen for useful suggestions.

\section{LITERATURE CITED}

Aebischer NJ, Coulson JC, Colebrook JM (1990) Parallel long-term trends across 4 marine trophic levels and weather. Nature 347:753-755

Ainley DG, Boekelheide RJ (1990) Seabirds of the Farallon Islands: ecology, dynamics, and structure of an upwellingsystem community. Stanford University Press, Stanford, CA

Ancel A, Kooyman GL, Ponganis PJ, Gendner JP and others (1992) Foraging behavior of emperor penguins as a resource detector in winter and summer. Nature 360: 336-339

Anderson DW, Gress F, Mais KF, Kelly PR (1980) Brown pelicans as anchovy stock indicators and their relationships to commercial fishing. CCOFI Rep 21:54-61

Asseburg C, Harwood J, Matthiopoulos J, Smout S (2006) The functional response of generalist predators and its implications for the monitoring of marine ecosystems. In: Boyd IL, Wanless S, Camphuysen CJ (eds) Top predators in marine ecosystems: their role in monitoring and management. Cambridge University Press, Cambridge, p 262-274

Barham PJ, Underhill LG, Crawford RJM, Leshoro TM, Bolton DA (2008) Impact of flipper-banding on breeding success of African penguins Spheniscus demersus at Robben Island: comparisons among silicone rubber bands, stainless steel bands and no bands. Afr J Mar Sci 30:595-602

Beckmen KB, Ylitalo GM, Towell RG, Krahn MM, O'Hara TM, Blake JE (1999) Factors affecting organochlorine contaminant concentrations in milk and blood of northern fur seal (Callorhinus ursinus) dams and pups from St. George Island, Alaska. Sci Total Environ 231:183-200

Bibby CJ (1999) Making the most of birds as environmental indicators. Ostrich 70:81-88

Birkhead TR, Furness RW (1985) Regulation of seabird populations. In: Sibly RM, Smith RH (eds) Behavioural ecology. Blackwell, Oxford, p 145-167

Birt VL, Birt TP, Goulet D, Cairns DK, Montevecchi WA (1987) Ashmole's halo: direct evidence for prey depletion by a seabird. Mar Ecol Prog Ser 40:205-208

Boersma PD (1978) Breeding patterns of Galapagos penguins as an indicator of oceanographic conditions. Science 200: 1481-1483

Bost CA, Le Maho Y (1993) Seabirds as bio-indicators of changing marine ecosystems: new perspectives. Acta Oecol Int J Ecol 14:463-470

Bost CA, Handrich Y, Butler PJ, Fahlman A, Halsey LG, Woakes AJ, Ropert-Coudert Y (2007) Changes in dive profiles as an indicator of feeding success in king and Adélie penguins. Deep-Sea Res II 54:248-255

Bost CA, Jaeger A, Huin W, Koubbi P, Halsey LG, Handrich Y (2008) Monitoring prey availability via data loggers deployed on seabirds: advances and present limitations. In: Tsukamoto K, Kawamura T, Takeuchi T, Beard TDJ, Kaiser MJ (eds) Fisheries for Global Welfare and Environment. 5th World Fisheries Congress, Yokohama, p 121-137

Bost CA, Cotté C, Bailleul F, Cherel Y and others (in press) (2009) The importance of oceanographic fronts to marine birds and mammals of the southern oceans. J Mar Syst doi:10.1016/j.jmarsys.2008.11.022 
Both C, Artemyev AV, Blaauw B, Cowie RJ and others (2004) Large-scale geographical variation confirms that climate change causes birds to lay earlier. Proc R Soc Lond B Biol Sci 271:1657-1662

Boyd IL, Wanless S, Camphuysen CJ (2006) Top predators in marine ecosystems: their role in monitoring and management. Cambridge University Press, Cambridge

Brown GB (1980) Seabirds as marine animals. In: Burger J, Olla HE, Winn HE (eds) Behavior of marine animals, Vol 4: Marine birds. Plenum Press, New York, p 1-39

$>$ Burger AE, Shaffer SA (2008) Perspectives in ornithology application of tracking and data-logging technology in research and conservation of seabirds. Auk 125:253-264

Cairns DK (1987) Seabirds as indicators of marine food supplies. Biol Oceanogr 5:261-271

Caro TM, O'Doherty G (1999) On the use of surrogate species in conservation biology. Conserv Biol 13:805-814

CCAMLR (2008) Ecosystem Monitoring Program. The Convention on the Conservation of Antarctic Marine Living Resources. Available at www.ccamlr.org/pu/e/sc/cemp/ intro.htm

Charrassin JB, Bost CA (2001) Utilisation of the oceanic habitat by king penguins over the annual cycle. Mar Ecol Prog Ser 221:285-297

Charrassin JB, Kato A, Handrich Y, Sato K and others (2001) Feeding behaviour of free-ranging penguins determined by oesophageal temperature. Proc R Soc Lond B Biol Sci 268:151-157

Charrassin JB, Park YH, Le Maho Y, Bost CA (2004) Fine resolution 3D temperature fields off Kerguelen from instrumented penguins. Deep-Sea Res I 51:2091-2103

Ciannelli L, Hjermann DØ, Lehodey P, Ottersen G, DuffyAnderson JT, Stenseth NC (2005) Climate forcing, food web structure, and community dynamics in pelagic marine ecosystems. In: Belgrano A, Scharler UM, Dunne J, Ulanowicz RE (eds) Aquatic food webs: an ecosystem approach. Oxford University Press, Oxford, p 143-169

Cotté C, Park YH, Guinet C, Bost CA (2007) Movements of foraging king penguins through marine mesoscale eddies. Proc R Soc Lond B Biol Sci 274:2385-2391

Crawford RJM (2007) Food, fishing and seabirds in the Benguela upwelling system. J Ornithol 148:253-260

Crawford RJM, Barham PJ, Underhill LG, Shannon LJ and others (2006a) The influence of food availability on breeding success of African penguins Spheniscus demersus at Robben Island, South Africa. Biol Conserv 132:119-125

Crawford RJM, Goya E, Roux JP, Zavalaga CB (2006b) Comparison of assemblages and some life-history traits of seabirds in the Humboldt and Benguela systems. Afr J Mar Sci 28:553-560

Crawford RJM, Sabarros PS, Fairweather T, Underhill LG, Wolfaardt AC (2008a) Implications for seabirds off South Africa of a long-term change in the distribution of sardine. Afr J Mar Sci 30:177-184

Crawford RJM, Tree AJ, Whittington PA, Visagie J and others (2008b) Recent distributional changes of seabirds in South Africa: Is climate having an impact? Afr J Mar Sci 30:189-193

Crick HQP, Dudley C, Glue DE, Thomson DL (1997) UK birds are laying eggs earlier. Nature 388:526

Croxall JP (1984) Seabirds. In: Laws R (ed) Antarctic ecology. Cambridge University Press, Cambridge, p 531-616

Croxall JP (1987) Seabirds: Feeding ecology and role in marine ecosystems. Cambridge University Press, Cambridge

Croxall JP, McCann TS, Prince PA, Rothery P (1988) Reproductive performance of seabirds and seals at South Georgia and Signy Island, South Orkney Islands, 1976-1987: implications for southern monitoring studies. In: Sahrage $\mathrm{D}$ (ed) Antartic ocean and resource variability. Springer Verlag, Berlin, p 516-533

> Cury P, Bakun A, Crawford RJM, Jarre A, Quinones RA, Shannon LJ, Verheye HM (2000) Small pelagics in upwelling systems: patterns of interaction and structural changes in 'wasp-waist' ecosystems. ICES J Mar Sci 57:603-618

> Cury PM, Shin YJ, Planque B, Durant JM and others (2008) Ecosystem oceanography for global change in fisheries. Trends Ecol Evol 23:338-346

Dugger KM, Ballard G, Ainley DG, Barton KJ (2006) Effects of flipper bands on foraging behavior and survival of Adelie penguins (Pygoscelis adeliae). Auk 123:858-869

> Durant JM, Anker-Nilssen T, Hjermann DØ, Stenseth NC (2004a) Regime shifts in the breeding of an Atlantic puffin population. Ecol Lett 7:388-394

Durant JM, Stenseth NC, Anker-Nilssen T, Harris MP, Thompson P, Wanless S (2004b) Marine ecosystems and climate variation: the North Atlantic. In: Stenseth NC, Ottersen G, Hurrell JW, Belgrano A (eds) Marine ecosystems and climate variation. Oxford University Press, Oxford, p 95-105

> Durant JM, Hjermann DØ, Anker-Nilssen T, Beaugrand G, Mysterud A, Pettorelli N, Stenseth NC (2005) Timing and abundance as key mechanisms affecting trophic interactions in variable environments. Ecol Lett 8:952-958

> Fauchald P (1999) Foraging in a hierarchical patch system. Am Nat 153:603-613

> Fauchald P, Tveraa T (2003) Using first-passage time in the analysis of area-restricted search and habitat selection. Ecology 84:282-288

Forchhammer MC, Post E, Stenseth N (1998) Breeding phenology and climate. Nature 391:29-30

> Forchhammer MC, Clutton-Brock TH, Lindström J, Albon S (2001) Climate and population density induce long-term cohort variation in a northern ungulate. J Anim Ecol 70:721-729

> Frederiksen M, Mavor RA, Wanless S (2007) Seabirds as environmental indicators: the advantages of combining data sets. Mar Ecol Prog Ser 352:205-211

Froget G, Gauthier-Clerc M, Le Maho Y, Handrich Y (1998) Is penguin banding harmless? Polar Biol 20:409-413

Furness RW, Camphuysen K (1997) Seabirds as monitors of the marine environment. ICES J Mar Sci 54:726-737

Furness RW, Greenwood JJD (1993) Birds as monitors of environmental change. Chapman \& Hall, London

Garthe S, Montevecchi WA, Davoren GK (2007) Flight destinations and foraging behaviour of northern gannets (Sula bassana) preying on a small forage fish in a low-Arctic ecosystem. Deep-Sea Res II 54:311-320

Gaston AJ, Gilchrist HG, Mallory ML (2005) Variation in ice conditions has strong effects on the breeding of marine birds at Prince Leopold Island, Nunavut. Ecography 28: 331-344

Gauthier-Clerc M, Gendner JP, Ribic CA, Fraser WR and others (2004) Long-term effects of flipper bands on penguins. Proc R Soc Lond B Biol Sci 271:423-426

Green AJ (2001) Mass/length residuals: Measures of body condition or generators of spurious results? Ecology 82: 1473-1483

Gregory RD, Noble D, Field R, Marchant JH, Raven M, Gibbons DW (2003) Using birds as indicators of biodiversity. Ornis Hungarica 12-13:11-24

> Gremillet D, Kuntz G, Delbart F, Mellet M and others (2004) Linking the foraging performance of a marine predator to local prey abundance. Funct Ecol 18:793-801

Gremillet D, Lewis S, Drapeau L, van Der Lingen CD and 
others (2008) Spatial match-mismatch in the Benguela upwelling zone: Should we expect chlorophyll and seasurface temperature to predict marine predator distributions? J Appl Ecol 45:610-621

Harding AM, Piatt JF, Sydeman WJ (2005) Bibliography of literature on seabirds as indicators of the marine environment. USGS Alaska Science Center, Anchorage, Alaska, p 20. Available at http://alaska.usgs.gov/science/biology/ seabirds_foragefish/sai/

Heslenfeld P, Enserink EL (2008) OSPAR Ecological Quality Objectives: the utility of health indicators for the North Sea. ICES J Mar Sci 65:1392-1397

Hilty J, Merenlender A (2000) Faunal indicator taxa selection for monitoring ecosystem health. Biol Conserv 92:185-197

Hunt GL, Eppley ZA, Schneider DC (1986) Reproductive performance of seabirds: the importance of population and colony size. Auk 103:306-317

Hunt GL, Piatt JF, Erikstadt KE (1990) How do foraging seabirds sample their environment? Acta XX Congressus Internationalis Ornithologici, Christchurch, New Zealand, p 2272-2280

Hunt GL Jr, Stabeno P, Walters G, Sinclair E, Brodeur RD, Napp JM, Bond NA (2002) Climate change and control of the southeastern Bering Sea pelagic ecosystem. Deep-Sea Res II 49:5821-5853

Hurrell JW (1995) Decadal trends in the North Atlantic Oscillation: regional temperatures and precipitations. Science 269:676-679

ICES (2003) Seabirds as monitors of the marine environment. In: Tasker ML, Furness RW (eds) Coop Res Rep 258. ICES, Copenhagen

> Jackson S, Wilson RP (2002) The potential costs of flipperbands to penguins. Funct Ecol 16:141-148

Jenouvrier S, Barbraud C, Weimerskirch H (2003) Effects of climate variability on the temporal population dynamics of southern fulmars. J Anim Ecol 72:576-587

Johnson CM (1980) Wintertime Arctic sea ice extremes and the simultaneous atmospheric circulation. Mon Weather Rev 108:1782-1791

Jonzen N, Linden A, Ergon T, Knudsen E and others (2006) Rapid advance of spring arrival dates in long-distance migratory birds. Science 312:1959-1961

Jonzen N, Ergon T, Linden A, Stenseth NC (2007) Introduction to CR Special 17: bird migration and climate. Clim Res $35: 1-3$

Jouventin P, Weimerskirch H (1991) Changes in the population size and demography of southern seabirds: management implications. In: Perrins CM, Lebreton JD, Hirons GJM (eds) Bird population studies: relevance to conservation and management. Blackwell Scientific Publication, Oxford, p 297-314

Le Bohec C, Durant JM, Gauthier-Clerc M, Stenseth NC and others (2008) King penguin population threatened by Southern Ocean warming. Proc Natl Acad Sci USA 105: 2493-2497

Litzow MA, Ciannelli L (2007) Oscillating trophic control induces community reorganization in a marine ecosystem. Ecol Lett 10:1124-1134

Lunn DJ, Thomas A, Best N, Spiegelhalter D (2000) Win BUGS - a Bayesian modelling framework: concepts, structure and extensibility. Stat Comput 10:325-337

Mills KL, Laidig T, Ralston S, Sydeman WJ (2007) Diets of top predators indicate pelagic juvenile rockfish (Sebastes spp.) abundance in the California Current System. Fish Oceanogr 16:273-283

Monaghan P (1996) Relevance of the behaviour of seabirds to the conservation of marine environments. Oikos 77 : $227-237$
Monaghan P, Uttley JD, Okill JD (1989) Terns and sandeels: seabirds as indicators of changes in marine fish populations. J Fish Biol 35 Issue sA:339-340

> Montevecchi WA (2007) Binary dietary responses of northern gannets Sula bassana indicate changing food web and oceanographic conditions. Mar Ecol Prog Ser 352:213-220

Montevecchi WA, Myers RA (1996) Dietary changes of seabirds indicate shifts in pelagic food webs. Sarsia 80:313-322

Mössner S, Ballschmiter K (1997) Marine mammals as global pollution indicators for organochlorines. Chemosphere 34:1285-1296

Nel DC, Lutjeharms JRE, Pakhomov EA, Ansorge IJ, Ryan PG, Klages NTW (2001) Exploitation of mesoscale oceanographic features by grey-headed albatross Thalassarche chrysostoma in the southern Indian Ocean. Mar Ecol Prog Ser 217:15-26

Nussey DH, Wilson AJ, Brommer JE (2007) The evolutionary ecology of individual phenotypic plasticity in wild populations. J Evol Biol 20:831-844

O'Connor RJ, Walls TE, Hughes RM (2000) Using multiple taxonomic groups to index the ecological condition of lakes. Environ Monit Assess 61:207-228

> Ottersen G, Planque B, Belgrano A, Post E, Reid PC, Stenseth NC (2001) Ecological effects of the North Atlantic Oscillation. Oecologia 128:1-14

Pakhomov EA, Perissinotto R, McQuaid CD (1994) Comparative structure of the macro-zooplankton/micronecton communities of the Subtropical and Antarctic Polar Fronts. Mar Ecol Prog Ser 111:155-169

Parrish JK, Zador SG (2003) Seabirds as indicators: An exploratory analysis of physical forcing in the Pacific Northwest coastal environment. Estuaries 26:1044-1057

Parsons M, Mitchell I, Butler A, Ratcliffe N, Frederiksen M, Foster S, Reid JB (2008) Seabirds as indicators of the marine environment. ICES J Mar Sci 65:1520-1526

Piatt IJF, Sydeman WJ, Wiese F (2007a) Introduction: seabirds as indicators of marine ecosystems. Mar Ecol Prog Ser 352:199-204

Piatt JF, Harding AMA, Shultz M, Speckman SG, van Pelt TI, Drew GS, Kettle AB (2007b) Seabirds as indicators of marine food supplies: Cairns revisited. Mar Ecol Prog Ser 352:221-234

Pinaud D, Weimerskirch H (2005) Scale-dependent habitat use in a long-ranging central place predator. J Anim Ecol 74:852-863

Reed TE, Wanless S, Harris MP, Frederiksen M, Kruuk LEB, Cunningham EJA (2006) Responding to environmental change: plastic responses vary little in a synchronous breeder. Proc R Soc Lond B Biol Sci 273:2713-2719

Reid K, Croxall JP, Briggs DR, Murphy EJ (2005) Antarctic ecosystem monitoring: quantifying the response of ecosystem indicators to variability in Antarctic krill. ICES J Mar Sci 62:366-373

Ricklefs RE (1990) Seabird life histories and the marine environment: some speculations. Colon Waterbirds 13:1-6

Robinson PW, Tremblay Y, Crocker DE, Kappes MA and others (2007) A comparison of indirect measures of feeding behaviour based on ARGOS tracking data. Deep-Sea Res II 54:356-368

Roemmich D, Owens W (2000) The Argo project. Global ocean observations for understanding and prediction of climate variability. Oceanography 13:45-50

Ropert-Coudert Y, Kato A, Wilson RP, Cannell B (2006) Foraging strategies and prey encounter rate of free-ranging little penguins. Mar Biol 149:139-148

Ropert-Coudert Y, Wilson RP, Yoda K, Kato A (2007) Assessing performance constraints in penguins with externally- 
attached devices. Mar Ecol Prog Ser 333:281-289

Schreer JF, Kovacs KM, Hines RJO (2001) Comparative diving patterns of pinnipeds and seabirds. Ecol Monogr 71:137-162

Schreiber EA, Burger J (eds) (2002) Biology of marine birds. CRC press, Boca Raton, FL

Schreiber RW, Schreiber EA (1984) Central Pacific seabirds and the El-Niño-Southern Oscillation: 1982-1983 perspectives. Science 225:713-716

Shaffer SA, Tremblay Y, Weimerskirch H, Scott D and others (2006) Migratory shearwaters integrate oceanic resources across the Pacific Ocean in an endless summer. Proc Natl Acad Sci USA 103:12799-12802

Smithers BV, Peck DR, Krockenberger AK, Congdon BC (2003) Elevated sea-surface temperature, reduced provisioning and reproductive failure of wedge-tailed shearwaters (Puffinus pacificus) in the southern Great Barrier Reef, Australia. Mar Freshw Res 54:973-977

Sokolov S, Rintoul SR, Wienecke B (2006) Tracking the Polar Front south of New Zealand using penguin dive data. Deep-Sea Res I 53:591-607

Stenseth NC, Mysterud A, Ottersen G, Hurrell JW, Chan KS, Lima M (2002) Ecological effects of climate fluctuations. Science 297:1292-1296

Strass VH, Naveira Garabato AC, Pollard RT, Fischer HI and others (2002) Mesoscale frontal dynamics: shaping the environment of primary production in the Antarctic Circumpolar Current. Deep-Sea Res II 49:3735-3769

Takahashi A, Dunn MJ, Trathan PN, Croxall JP, Wilson RP, Sato K, Naito Y (2004) Krill-feeding behaviour in a chinstrap penguin Pygoscelis antarctica compared with fisheating in Magellanic penguins Spheniscus magellanicus: a pilot study. Mar Ornithol 32:47-54

Thompson PM, Grosbois V (2002) Effects of climate variation on seabird population dynamics. Dir Sci 1:50-52

Thompson PM, Ollason JC (2001) Lagged effects of ocean climate change on fulmar population dynamics. Nature 413:417-420

Trathan PN, Green C, Tanton J, Peat H, Poncet J, Morton A (2006) Foraging dynamics of macaroni penguins Eudyptes chrysolophus at South Georgia during brood-guard. Mar Ecol Prog Ser 323:239-251

Visser ME, Both C (2005) Shifts in phenology due to global climate change: the need for a yardstick. Proc R Soc Lond B Biol Sci 272:2561-2569

> Votier SC, Bearhop S, Attrill MJ, Oro D (2008) Is climate change the most likely driver of range expansion for a critically endangered top predator in northeast Atlantic waters? Biol Lett 4:204-205

- Walther GR, Post E, Convey P, Menzel A and others (2002)
Ecological responses to recent climate change. Nature 416:389-395

Wanless S, Frederiksen M, Walton J, Harris MP (2009) Longterm changes in breeding phenology at two seabird colonies in the northwestern North Sea. Ibis 151:274-285

Warton DI (2007) smatr: (standardised) major axis estimation and testing routines ( $\mathrm{R}$ package version 2.1 ). Available at http://cran.r-project.org/web/packages/smatr/index.html

> Warton DI, Wright IJ, Falster DS, Westoby M (2006) Bivariate line-fitting methods for allometry. Biol Rev Camb Philos Soc 81:259-291

Watanabe Y, Bornemann H, Liebsch N, Plötz J, Sato K, Naito Y, Miyazaki N (2006) Seal-mounted cameras detect invertebrate fauna on the underside of an Antarctic ice shelf. Mar Ecol Prog Ser 309:297-300

Watanuki Y, Daunt F, Takahashi A, Newell M, Wanless S, Sato K, Miyazaki N (2008) Microhabitat use and prey capture of a bottom-feeding top predator, the European shag, shown by camera loggers. Mar Ecol Prog Ser 356:283-293

Weimerskirch H (2002) Seabird demography and its relationship with the marine environment. In: Schreiber EA, Burger J (eds) Biology of marine birds. CRC Press, Boca Raton, FL, p 115-135

Weimerskirch H (2007) Are seabirds foraging for unpredictable resources? Deep-Sea Res II 54:211-223

> Weimerskirch H, Wilson RP, Guinet C, Koudil M (1995) Use of seabirds to monitor sea-surface temperatures and to validate satellite remote-sensing measurements in the Southern Ocean. Mar Ecol Prog Ser 126:299-303

> Weimerskirch H, Pinaud D, Pawlowski F, Bost CA (2007) Does prey capture induce area-restricted search? A fine-scale study using GPS in a marine predator, the wandering albatross. Am Nat 170:734-743

Weise MJ, Costa DP, Kudela RM (2006) Movement and diving behavior of male California sea lion (Zalophus californianus) during anomalous oceanographic conditions of 2005 compared to those of 2004. Geophys Res Lett 33:L22S10

Wilson RP, Grémillet D, Syder J, Kierspel MAM and others (2002a) Remote-sensing systems and seabirds: their use, abuse and potential for measuring marine environmental variables. Mar Ecol Prog Ser 228:241-261

Wilson RP, Steinfurth A, Ropert-Coudert Y, Kato A, Kurita M (2002b) Lip-reading in remote subjects: an attempt to quantify and separate ingestion, breathing and vocalisation in free-living animals using penguins as a model. Mar Biol 140:17-27

Wilson RP, Liebsch N, Davies IM, Quintana F and others (2007) All at sea with animal tracks: methodological and analytical solutions for the resolution of movement. DeepSea Res II 54:193-210

Appendix 1. Seabirds as oceanographic autonomous samplers

Given the paucity of information on temporal and spatial distribution of zooplankton and nekton in the oceans, a valuable input of instrumented seabirds could be their ability to indicate and sample places of enhanced biological activity. Indeed, during their foraging trips at sea, seabirds actively search, locate, and capture prey. Therefore, their 2D (at the sea surface) or 3D (at depth) movements are necessarily inclusive of all information on prey location. When information on prey ingestion (feeding behaviour) can be obtained concomitantly with feeding location, instrumented seabirds have the potential to provide data on prey distribution and relative prey abundance. The relevance of this concept depends on 2 factors: (1) the validity of proxies used to infer feeding behaviour and prey distribution from seabird movements (2) the scale at which the relationships between seabirds and the prey field is examined.

At-sea tracking of seabirds is based on miniaturised electronic devices attached to the animals that transmit or log data on horizontal and/or vertical bird positions over time. Horizontal positioning methods include satellite telemetry (e.g. Charrassin \& Bost 2001), GPS localisation (Weimerskirch et al. 2007), geolocation (Shaffer et al. 2006), and dead reckoning (that calculates animal movements based on speed, heading and changes in depth; see review by Wilson et al. 2007). Vertical positioning, i.e. diving behaviour, is obtained by logging hydrostatic pressure according to time 
Appendix 1 (continued)

with frequencies ranging from one sample every few minutes to several Hz (e.g. Schreer et al. 2001). Depending on positioning errors and spatial and temporal resolution inherent to each technique, a variety of proxies and adapted statistical inferences were devised to translate seabird 2D or 3D positions over time in terms of foraging effort, foraging success and zones of biological importance.

Marine predator movements are complex as they integrate and reflect the hierarchical distribution of prey along different scales in the ocean (Fauchald \& Tveraa 2003).

Large and mesoscale (100 km and more). Fronts are generally known to be zones of enhanced biological productivity through underlying physical enrichment. In the Southern Ocean, large oceanic features such as the Polar and Subantarctic Fronts are relatively well known, from a limited number of ship-based surveys, as productive belts (e.g. Pakhomov et al. 1994). Bost et al. (2009) reviewed relevant examples of indication by instrumented seabirds, at several localities and over several years, on the key role of these oceanic large-scale structures as summer feeding grounds and confirmed the key role of the oceanic fronts for marine resource distribution. These tracking studies revealed that several species of penguins (king, royal and macaroni) and albatross (grey-headed and black-browed) were mainly feeding (on myctophids, krill, or squids) at the Polar and Subantarctic Fronts, as inferred by birds increasing the relative time spent per sector or slowing down at these fronts (Trathan et al. 2006, Bost et al. 2009). Mesoscale features (100 to $200 \mathrm{~km}$ ) such as eddies and their associated fronts were recently identified as hotspots of seabird feeding activity. Some analysis confronting satellite tracks to concurrent altimetry-derived SSH maps (allowing to identify eddies) demonstrated that both penguins (Cotté et al. 2007) and volant seabirds ( $\mathrm{Nel}$ et al. 2001) focused their foraging effort at the internal or external border of mesoscale eddies. Although distribution of primary production at the sea surface is accessible via remote sensing (such as SeaWiFS satellite images), large to mesoscale distributional data on secondary or tertiary production is more seldom for remote oceans. In this context, seabirds, and, more generally, pelagic predators have the potential to provide indirect but original evidence on prey aggregation in relation to physical discontinuities.

Smaller scales and detection of feeding. At scales of up to $100 \mathrm{~km}, 2 \mathrm{D}$ movements at sea surface are examined in order to extract regions of area-restricted search (ARS), where a predator changes its behaviour from broadly unidirectional travelling to multidirectional and highly sinuous food search movements. The latter behaviour is assumed to be a response to the presence of prey and/or to environmental cues (Fauchald 1999). Analysis of first passage time in circles of increasing radius along the seabird path was used to investigate the scales at which satellite-tracked prions and albatross operate (Fauchald \& Tveraa 2003). It was shown that birds were using different scales of searching behaviour from mesoscale $(130-240 \mathrm{~km})$ to scales down to 20 to $30 \mathrm{~km}$ (Fauchald \& Tveraa 2003, Pinaud \& Weimerskirch 2005) which probably reflected prey aggregation patterns at these different scales. However, a fine scale study in wandering albatross, combining GPS tracking and feeding events (as revealed by drops in stomach temperature induced by cold prey ingestion) showed that only $13 \%$ of highly sinuous movements started after prey ingestion, suggesting that such behaviour did not mean that birds had actually encountered prey. Rather, most of the intensive searching behaviour was thought to occur in response to environmental cues (e.g. odour or visual cues particular to the shelf break, or presence of feeding congeners; Weimerskirch et al. 2007). In contrast to
Argos satellite tracking that features temporal and spatial resolutions too low to detect small scale ARS (Robinson et al. 2007), GPS tracking and high resolution dead-reckoning (Wilson et al. 2007) appear adapted to detect fine scale shifts in searching behaviour. However, such changes do not necessarily indicate encounter of prey, and should be combined with detection of feeding events in order to determine prey distribution at a fine scale. With regards to diving birds, inferring feeding behaviour from dive-based only parameters (such as time at the bottom) has long been problematic due to the lack of simultaneous data on vertical prey distribution for validation of proxies. Measurements of temperature drop in the stomach and oesophagus were used to directly monitor prey ingestion during diving (e.g. Charrassin et al. 2001). As a refinement to these techniques, recording of beak openings during diving is probably currently the most accurate method to monitor prey ingestion in diving seabirds (Wilson et al. $2002 b)$. The comparison of beak openings with high resolution dive profiles showed that the bottom phase durationand even more so, the number of wiggles at depth (up and down movements of the bird while swimming at the bottom phase of the dive) - are good indicators of feeding (Takahashi et al. 2004, Bost et al. 2007, Bost et al. 2008). Change in stroke frequencies (e.g. of flippers in penguins) recorded by accelerometers is also an accurate proxy of prey encounter and therefore an indicator of the presence of prey at the corresponding depth (Ropert-Coudert et al. 2006). Both methods share the advantage of being very practical and their use is likely to expand with progress in technology. Finally, animalborne cameras taking still pictures or videos able to monitor the prey field at depth are now available for birds (Watanuki et al. 2008) and may soon allow a more quantitative estimation of prey abundance in the water column.

Comparisons of seabird foraging activity with concurrent prey fields are rare and mainly concern coastal species with a limited range of operation. They usually provide mixed results concerning bio-indication of prey aggregation by foraging birds. In western Greenland, great cormorants showed a high foraging efficiency in an environment with low prey abundance (Gremillet et al. 2004). GPS-tracked cape gannets from the South African Atlantic coast appeared restricted to an area of the Benguela current system that no longer supports high anchovies and sardines, due to a recent regime shift, which resulted in poor foraging success and a marked decline in population (Crawford et al. 2008a). This was attributed to the inability of seabirds with a limited foraging range to track the large scale movement of their prey (Gremillet et al. 2008). Conversely, distributions of GPS-tracked northern gannets foraging in the northwest Atlantic showed a strong correspondence with the coastal and inshore aggregation of their main prey; capelins (Garthe et al. 2007).

In conclusion, track-based data can provide information on the presence of prey from the mesoscale to the large scale and it is generally more efficient to obtain these data from longranging seabirds than from other seabirds. At smaller scales, direct feeding measurements (or validated proxies of feeding or prey encounter) may be required in addition to high resolution data on bird position at the surface and at depth. Future challenges lie in increasing the sample size and in the corollary development of adequate methods to analyse the huge volume of data acquired, and in validating the track-based and feeding proxies used to evaluate prey distribution and relative abundance with concurrent expensive vessel-based campaigns. However, given the steady progress in technology and the associated decrease in costs of data acquisition, along with ever finer temporal and spatial resolution, the concept of using tracked seabirds as bio-indicators faces a promising future. 
Appendix 2. Statistical considerations: imprecision and inverse inference error

One role of bioindicators is to estimate the abundance (or availability) of species at lower trophic levels - when such estimates are not available-by using the value of the bioindicator and the statistical relationship linking the 2 variables. There are 2 basic steps for this procedure: Step 1 is to establish (based on data for particular areas or years) the relationship between prey abundance and predator performance; Step 2 is to use monitoring data of predator performance (for other particular areas or years) to predict prey abundance using the relationship found in Step 1. Asseburg et al. (2006) pointed out 3 difficulties of such 'inverse inference' while working on the framework of functional responses (predator consumption as a function of prey abundance).

(1) There is parameter uncertainty in the functional response found in Step 1 (we could add model uncertainty, as there may be alternative mathematical models for functional responses).

(2) The functional response typically has a sigmoid shape, meaning that even with perfect knowledge of the functional response, uncertainty in the measurement of predator consumption (Step 2) can translate into a large uncertainty of prey density in the flat parts of the sigmoid curve (i.e. for low and high values of predator consumption).
(3) There may be uncertainty about the abundance of alternative prey and how they affect predator consumption.

Here we will consider how statistical assumptions are often ignored in Step 1. Let us (for simplicity) consider a linear relationship between an ecosystem state variable, e.g. prey abundance $(X)$ and predator performance (the bioindicator, $Y$ ). Typically, this relationship is established using ordinary least square (OLS) regression:

$$
Y=a+b X+\varepsilon
$$

where $a$ and $b$ are estimated parameters (intercept and slope), and $\varepsilon$ is residual variance, assumed to be normally distributed around zero. Thus, when the bioindicator $Y$ is known and the ecosystem state variable $X$ is unknown, a researcher can find $X$ using the formula $X=(Y-a) / b$ (Fig. A1). However, OLS regression has 2 important assumptions regarding this aspect (Green 2001): (i) $Y$ is affected by $X$ while $X$ is strictly independent of $Y$ (for instance an experimental setting where the experimenter sets the values of $X$ ); (ii) there is no measurement error (including sampling error) in $X$. Assumption (i) may not hold if, for instance, the reproductive success of birds affects the abundance of fish. Here we will not deal with this issue, which is fairly complicated to deal with analytically.
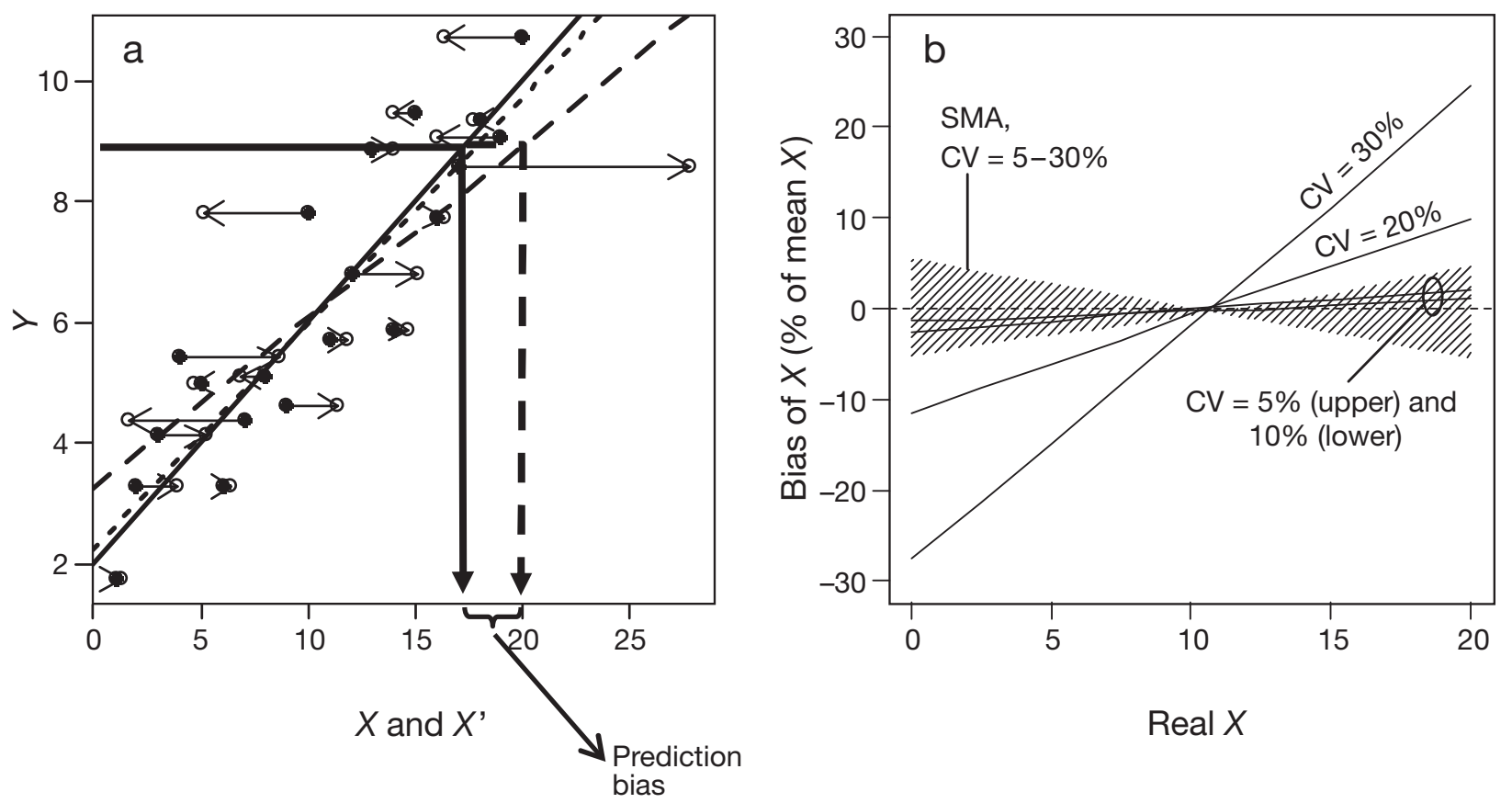

Fig. A1. (a) An example showing the effect of measurement noise in the ecosystem variable $(X)$ on regression $\left(X^{\prime}\right)$. The black dots are the real values ( $X Y$ pairs) from Eq. (1), while the white dots are the data with observation error added to $X\left(X^{\prime} Y\right.$ pairs; see Eq.[2]). The thin arrows indicate the effect of observation error in $X$ ( $\delta$ in Eq. [2]). The unbroken line is the real (unknown) relationship between $X$ and $Y(Y=2+0.4 X)$, the dashed line is the relationship estimated using ordinary least squares (OLS) regression, and the dotted line is the relationship estimated using standardized major axis (SMA) regression. The thick continuous arrow shows the correct $X$ values, while the thick dashed arrow shows the biased $X$ value that results if OLS regression is used to predict $X$ from $Y$. (b) Bias when $X$ is predicted from $Y$, using OLS and SMA regression. The lines show the bias (as a percentage of the mean $X$ value) for the OLS method for a given amount of measurement error $(\delta)$, given as the coefficient of variation (CV). When the measurement error exceeds $10 \%$, the bias of the OLS method becomes substantial. For predictions close to the mean $X$ value, however, bias is always small. The bias of the SMA method (indicated by the shaded area) is always small, regardless of the magnitude of measurement error 
Appendix 2 (continued)

Assumption (ii) never holds in practice. However, alternative statistical methods exist to deal with this problem: major axis regression (MA) and standardized major axis regression (SMA). In contrast to OLS regression (also referred to as 'Model I regression'), the MA and SMA methods ('Model II regression') allow for error in both variables. Also, these methods do not distinguish between 'dependent' and 'independent' variables (i.e. do not assume a one-way causal link from $X$ to $Y$ ). These methods have been reviewed by Warton et al. (2006).

We did a simple test to see how observation error in the $X$ variable affects 'inverse' predictions of $X$ from observed $Y$ values. We let $X$ influence $Y$ linearly, as in Eq. (1). However, we cannot observe $X$ directly, but instead observe $X$ with added measurement noise, $X^{\prime}$ :

$$
X^{\prime}=X+\delta
$$

where $\delta$ is the observation error of $X$ (assumed to be normally distributed around zero). We let $X$ be the values 1,2 , $\ldots, 20$ (i.e. sample size $=20$ ) and predicted $Y$ assuming this and using Eq. (1) with arbitrary values for the constants $(a=$ $2, b=0.4$ ) and with the standard deviation of $\varepsilon$ being equal to 1 , i.e. the coefficient of variation $(\mathrm{CV})$ of $\varepsilon$ is $16 \%$ (departure from the regression line as a percentage of the mean value of $a+b X)$. Assuming that we did not know the real values of $a$ and $b$, we simulated that we observed $X^{\prime}$ and then performed regression on the $X^{\prime}$ and $Y$ data using the OLS, MA and SMA methods (using the smatr library in R v.2.1 from Warton 2007); i.e. Step 1 above. Step 2 was carried out by using the estimated $a$ and $b$ values to predict $X$ from 3 different $Y$ values ( $Y=4,6$ and 8, see Fig. A1a). We used 4 different levels of measurement error in $X$, letting the $\mathrm{CV}$ of $\delta$ vary from 5 to $30 \%$. For each of the 4 levels we ran 1000 replicates. We found that when the CV was 5 or $10 \%$ (i.e. when the observation error of $X$ was smaller than the model error $\varepsilon$ ), the 3 methods gave similar results. However, when the CV was 20 or $30 \%$, the estimates of OLS were clearly biased, while the SMA method returned unbiased estimates. The MA method yielded a bias similar to OLS. As shown in Fig. A1a, the OLS and MA methods tended to underestimate the slope $b$, thereby underestimating low $X$ values and overestimating large $X$ values (Fig. A1b). Thus SMA is a better method than OLS when the measurement or sampling error in $X$ is large or of unknown magnitude. We advise the use of SMA rather than OLS when bioindicators are used to predict e.g. prey abundance. Alternatively, Bayesian methods (e.g. using the WinBUGS program; Lunn et al. 2000) are also an option.

Appendix 3. Combining ecological time series: Univariate or multivariate indicators?

One of the aims of selecting specific indicators to describe change in ecological systems is the need to avoid potential 'data overload' associated with presenting all available ecological time series. At the same time, the selected indicator(s) should be representative of general patterns in major ecosystem components. Under these constraints, selecting one or a set of univariate indicators is not unproblematic. Each measured variable is likely to be affected by a range of environmental drivers, only some of which are of general relevance. Measurement error will also tend to obscure statistical relationships between measured variables and environmental drivers. Thus, any single indicator may be unrepresentative of the system under study, and selecting a suite of indicators may lead to immersion in detail and loss of perspective.

Multivariate statistics can potentially resolve some of these problems if sufficient data are available. For instance, principal component analysis (PCA) extracts the strongest common linear signal from a set of variables, in this context ecological time series. Several properties make the first principal component (PC1) an attractive choice as a compound ecological indicator, if (and only if) the constituent time series are reasonably highly correlated. Firstly, 'noise' in the original time series, such as measurement error and species- or location-specific relationships with environmental drivers, will tend to get filtered out, leaving a common signal that should ideally be more tightly correlated with an assumed common driver than with any of the original variables (Reid et al. 2005, Frederiksen et al. 2007). Secondly, the proportion of the total variation in the data set explained by $\mathrm{PC} 1$, as well as the correlations with each original time series, are readily quantified in standard software, so that the statistical performance of the indicator can be evaluated. Multivariate indicators are well established in e.g. water quality assessment (e.g. O'Connor et al. 2000), but have seen much less use in vertebrate studies where attention usually has focused on individual species.

As mentioned, multivariate indicators are only meaningful if the original time series are correlated in space and/or across species. This is more likely to be the case if the system is dominated by bottom-up control, potentially driven by large-scale climate factors. Multivariate indicators may be particularly well suited to monitoring the effects of climate change on marine systems, for instance using seabirds and other marine top predators, because several recent studies indicate that high between-time series correlations are common for these groups (Reid et al. 2005, Frederiksen et al. 2007, Mills et al. 2007, Wanless et al. 2009).

Apart from the need for extensive data on which to base the calculations, multivariate indicators have a few other drawbacks, mostly related to presentation and interpretability. Although e.g. a 'seabird performance index' is likely to be more representative than breeding success of one species, it may be more difficult for managers and the general public to relate to. In this context, results of the PCA show which of the original time series is most highly correlated with the PC1, and this variable could be viewed as the most representative univariate indicator. Furthermore, values of the PC1 index will change retrospectively each time it is recalculated (e.g. every year), because they depend on the correlation structure of the entire data set. However, preliminary analyses indicate that such changes are small, once 10 to 15 years of data have accumulated (M. Frederiksen pers. comm.). 